\title{
Batrachochytrium salamandrivorans
}

\section{1) Author names, affiliations, email for correspondence}

\author{
Rhys A. Farrer
}

Medical Research Council Centre for Medical Mycology at the University of Aberdeen, Aberdeen Fungal Group, Institute of Medical Sciences, Foresterhill, Aberdeen, UK rhys.farrer@abdn.ac.uk

\section{2) Summary}

The recently discovered Batrachochytrium salamandivorans (Bsal) is a fungal pathogen of salamanders and newts, which has recently spread from Asia into Europe devastating the fire salamander. The disease is characterised by multifocal superficial erosions and deep ulcerations in the skin of salamanders, with several European species particularly susceptible. Although seemingly unaffected, the Anura (frogs and toads) can also act as Bsal carriers, with anthropogenic trade and inter/intra-species contact likely spreading the disease. Bsal is closely related to the generalist amphibian pathogen $B$. dendrobatidis $(B d)$, which was discovered two decades prior. The genome of $B s a l$ is larger $(32 \mathrm{Mb})$ than $B d$ 's $(23 \mathrm{Mb})$ and encodes over a hundred metalloprotease M36 genes, correlating with its ulcerative pathology. Further work on the population genetics of $B s a l$ and genetic differences between $B d$ and $B$ sal should uncover the mechanisms behind their differences in host specificity, pathology and epidemiology.

\section{3) Bullet point list of Key Facts and Disease Facts}

\section{Key Facts:}

$\rightarrow$ Bsal was discovered in 2013.

$\rightarrow$ It causes multifocal superficial erosions and deep ulcerations in the skin of Caudatan species (salamanders and newts) unlike its sister species $B$. dendrobatidis, which causes a thickening of the skin (hyperplasia and hyperkeratosis) and is a generalist amphibian pathogen.

$\rightarrow$ It grows between $5-25^{\circ} \mathrm{C}$, with optimal growth between $10-15^{\circ} \mathrm{C}$.

$\rightarrow$ Like other chytrids, Bsal reproduces with motile spores (zoospores) that emerge from zoosporangia.

$\rightarrow$ The ancestral range of $B$. salamandrivorans appears to be southeast Asia, with a widespread distribution in Vietnam.

$\rightarrow$ Bsal spread from Asia into Europe, causing the near extirpation of fire salamanders (Salamandra Salamandra) in the Netherlands in 2013.

$\rightarrow \mathrm{Bsal}$ is not found in salamander biodiverse regions such as North America, supported by the U.S. Fish and Wildlife Commission banning the import of 201 species of salamanders into the USA in 2016.

$\rightarrow$ The genome of $B s a l$ is much larger than that of $B d$ and it contains three times the number of secreted metalloprotease M36 genes that encode proteins that are thought to degrade host tissue; this correlates with that ulcerative pathology caused by Bsal. 
$\rightarrow$ M36s and a large uncharacterised secreted tribe (Tribe 1) are upregulated during infection of a salamander host (Tylototriton wenxianensis).

$\rightarrow B s a l$ infection had little effect on salamander mRNA levels compared with $B d$ infection. Innate and adaptive immune response genes were not upregulated, suggesting potential immune-dampening properties.

\title{
4) Taxonomic and Classification information
}

\author{
Kingdom Fungi \\ Phylum Chytridiomycota \\ Order Rhizophydiales \\ Genus Batrachochytrium \\ Species salamandrivorans
}

\section{5) References}

1. Martel, A. et al. Batrachochytrium salamandrivorans sp. nov. causes lethal chytridiomycosis in amphibians. Proc. Natl. Acad. Sci. U. S. A. 110, 15325-15329 (2013).

2. Martel, A. et al. Wildlife disease. Recent introduction of a chytrid fungus endangers Western Palearctic salamanders. Science 346, 630-631 (2014).

3. Nguyen, T. T., Nguyen, T. V., Ziegler, T., Pasmans, F. \& Martel, A. Trade in wild anurans vectors the urodelan pathogen Batrachochytrium salamandrivorans into Europe. Amphib.-Reptil. 38, 554-556 (2017).

4. More, S. et al. Risk of survival, establishment and spread of Batrachochytrium salamandrivorans (Bsal) in the EU. EFSA J. 16, e05259 (2018).

5. Berger, L. et al. Chytridiomycosis causes amphibian mortality associated with population declines in the rain forests of Australia and Central America. Proc. Natl. Acad. Sci. U. S. A. 95, 9031-9036 (1998).

6. Olson, D. H. et al. Mapping the global emergence of Batrachochytrium dendrobatidis, the amphibian chytrid fungus. PloS One 8, e56802 (2013).

7. O'Hanlon, S. J. et al. Recent Asian origin of chytrid fungi causing global amphibian declines. Science 360, 621-627 (2018).

8. Farrer, R. A. et al. Describing genomic and epigenomic traits underpinning emerging fungal pathogens. Adv. Genet. 100, 73-140 (2017). 
9. Fisher, M. C. et al. Outbreaks and the emergence of novel fungal infections: lessons from the panzootic of amphibian chytridiomycosis. J. Invasive Fungal Infect. 5, 73-81 (2011).

10. Farrer, R. A. et al. Genomic innovations linked to infection strategies across emerging pathogenic chytrid fungi. Nat. Commun. 8, 14742 (2017).

\section{6) Keywords}

Batrachochytrium salamandivorans

Chytrid

Salamander

Amphibian

\section{Acknowledgements}

An Martel, University of Ghent, provided the micrograph of $B$. salamandrivorans where $B s a l$ sporangia develop discharge tubes (arrow) to release zoospores and (right) a scanning electron microscopic image of Bsal with rhizoids. Duncan Wilson and Matthew Fisher provided valuable comments. 

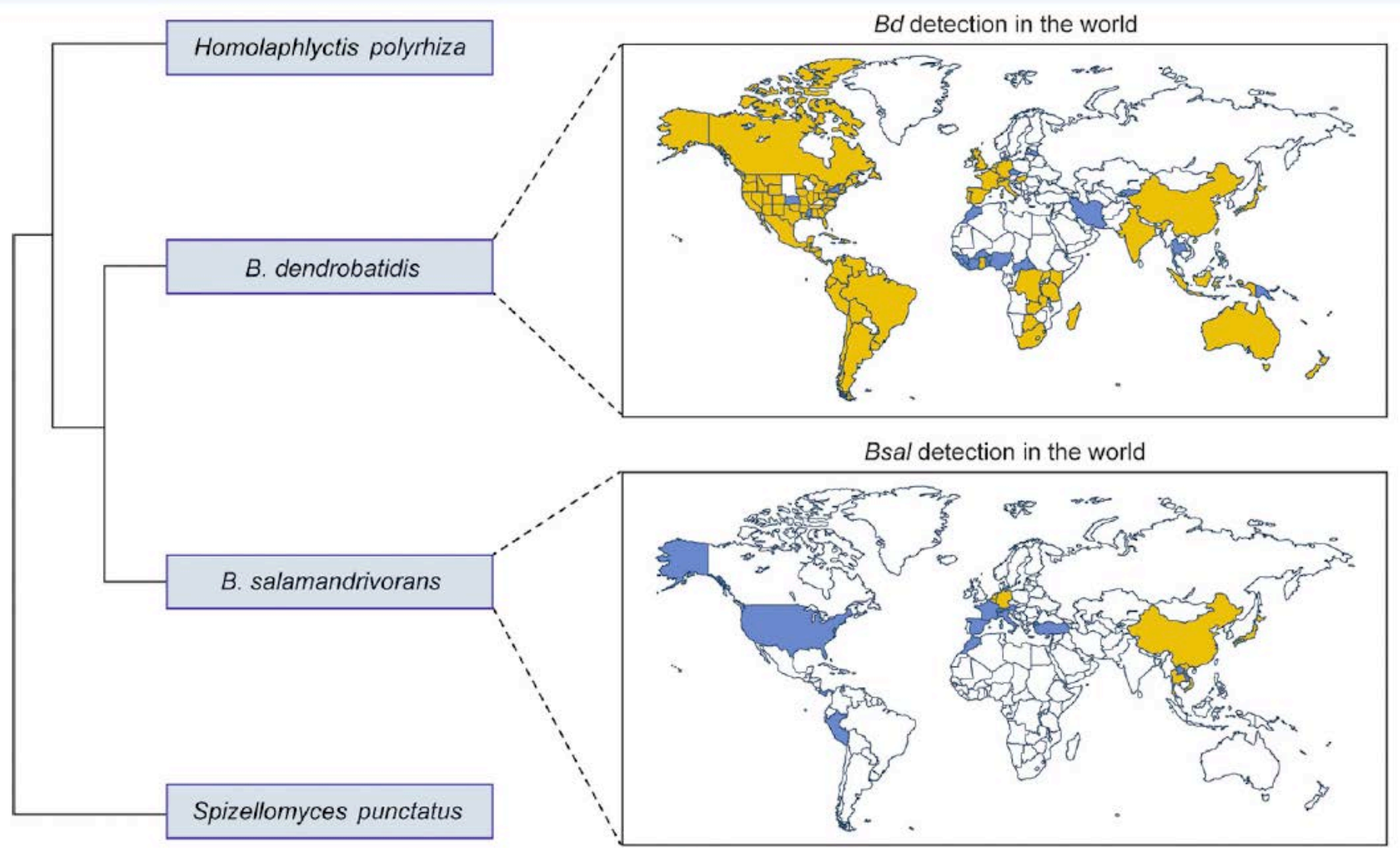

Positive samples 
A) $\quad$ B)

A) $\quad$ B)
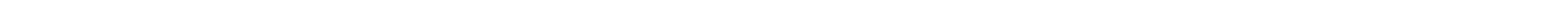

$0593.12 \mathrm{KV} \quad \mathrm{X}_{2} ; 50.10 \mathrm{Hm}$. WD30
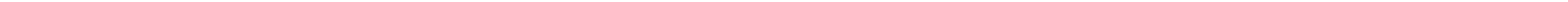